\title{
Lifelong Learning for UK Researchers in Higher Education
}

\author{
Lisa Worrall \\ University of East Anglia, United Kingdom
}

\begin{abstract}
This paper outlines the first cycle of an Action Research (AR) investigation into why UK researchers are under-utilizing the training and career support on offer. The ontological and epistemological stance of the author is stated along with how this impacted upon the research process. This paper outlines the specific AR approach used and discusses the constraints that surround this type of research. The first cycle of $A R$ revealed that many researchers believe that their Principal Investigator would be unwilling to offer them the time needed to undertake training. This perceived barrier was raised at an executive level; resulting in a universitywide policy document that stated that all staff were entitled to at least two days training per annum. This paper outlines how the research was undertaken and disseminated and concludes that when used in a contextually valid setting, how AR can lead to swift and substantial improvements within institutions.
\end{abstract}

\section{Introduction}

The rationale for this research is to attempt to understand the under-utilization of Continuous Professional Development (CPD) training opportunities by researchers based within the University of East Anglia (UEA). Although this investigation is unable to generalize its findings beyond the context of this study, it is hoped that the lessons learned may be of some use to other Higher Education (HE) organizations. The UEA researcher staff based within UEA often experience transient (if any) contact with colleagues beyond the remit of their own research project. Indeed, researchers have often commented to the author that they sometimes feel that they are existing inside a 'research bubble', whereby their awareness of other colleagues and the wider university is vague at best. The author acts as the Staff Development Officer for Researchers (SDO-R). As such, the author is in charge of ensuring that the Continuous Professional Development (CPD) needs of researchers are met. However, upon commencing this role, it immediately became apparent that there was a wide-spread underutilization of the CPD training opportunities that were on offer to researchers. Although some of this might be due to their relative isolation within their research projects, initial face-to-face enquiries revealed a far more complex picture that merited further investigation.

Within the UK, whereas academics enjoy the relative stability of a permanent contract, researchers face career instability, as they exist on a series of fixed-term contracts in order to remain in employment. Due to the high chance of experiencing gaps in their employment status, researchers, even more than their academic counterparts, need to maintain a competitive edge in the job market in order to maximize their chances of swiftly obtaining another research contract. Therefore, the low uptake of free CPD training opportunities that could enhance their employability potential was of a particular concern to the author, who viewed it as important to find out why this was happening.

The ontological and epistemological perspective of the author is based upon social constructivism. This perspective emerged after a number of years of the author exploring differing viewpoints regarding the nature of the world and of knowledge. The author views knowledge as being a socially constructed process, which is subject to selective interpretation and retention within differing contexts and environments. Educators are merely the facilitators of knowledge retention which is in turn, deepened by processes of self-reflection and collaboration [8]. Learning occurs when knowledge is reflected upon regarding its relevance, interest and use to the individual. Learner engagement also needs to occur within the learner's 'zones of proximal development' of what can be learned without help, compared to what can be achieved with the appropriate learning facilitation and guidance [11]. Learning is affected by collaborations with peers, the learning facilitator as well as with the context in which it is situated.

This awareness of context within a social constructivist stance, will aid in the design and evaluation of the research and also offer guidance in areas of practice that need to change [10]. The inherent values and beliefs of the author embrace freedom, learner empowerment, and Equality and Diversity (E\&D) which the author considers to be universal values that need to be held by all modern day learning facilitators and staff development officers. Although the researchers are not students in the traditional sense of Higher Education (HE), they 
form a part of a legitimate learning cohort based at UEA and they are considered to be highly valued members of staff within the organization.

\section{Relevant Literature}

Action Research (AR) encompasses at its heart, 'research through action' and is a collaborative process whereby feedback from individuals or groups (e.g. researchers) can yield critical insights that can bring about proactive changes; either to an environment, a system or a process, be this singularly in themselves or taken as a whole. With each change that is actioned within its specific context, practitioners can learn more about what works and, equally importantly, what does not. Each cycle of research and action can lead to continuous improvements. The founder of AR, Kurt Lewin, accurately summarizes the function, purpose and power of AR by stating, "If you want truly to understand something, try to change it" [7].

In $\mathrm{AR}$, behavior is seen as the function of an individual's characteristics and also of the environment or context in which it is situated. This powerful methodology was taken up by the teacher/practitioner movement in the 1970s-80s and it led to the view that the design, process and theory of learning is mutually dependent within proactive cycles of continuous improvements. Kolb [6] was also heavily influenced by AR in his four stage cycle model of experiential learning which argues that individuals learn via processes of concrete experience, reflective observation, abstract conceptualization and active experimentation.

AR recognizes the need for a methodical, iterative approach in identifying problems, action planning, implementation, evaluation and critical reflection. What the practitioner learns through each cycle of AR guides their second, third and fourth cycles, and so on [3]. However, there are four identifiable AR approaches that can be distinguished from one another; these being traditional, radical, educational and contextual. Traditional AR focuses upon the importance of worker-management relations, information systems and of democracy while maintaining the status quo but focuses upon changes in power structures. Radical AR has its roots in Marxist theory and focuses upon emancipation and the overcoming of power structures. It is also often utilized as part of Feminist AR, which centers upon the emancipation of minority groups in society. Educational AR focuses upon the role of teachers/facilitators in the education sector and states that educators need to be more involved in community issues, the curriculum, CPD and learning in particular. AR researchers in HE can utilize the educational AR approach to also investigate primary and secondary school teachers on community projects. The fourth approach is known as contextual
AR (which is the approach that the author has chosen). This approach views learning as contextual in that it is affected by the social environment. Learners are seen as both designers and coresearchers in advancing learning design, process and delivery. Change is seen as a consensus based process of learning through action, self-reflection and iterative feedback within an ongoing collaborative process of continuous improvement.

The author acknowledges that learning specialisms and requirements will differ across various universities, Departments and Faculties, both over time as well as according to differing contexts and environments. Biglan argues that differing disciplines can view the nature of knowledge and research methods differently [2]. For example, 'hard disciplines' are typified as atomistic, cumulative, competitive and quantitative, whereas 'soft disciplines' are reiterative, holistic, collaborative and more qualitative. Pure and hard knowledge is more concerned with mastery of protocols, tools and techniques and outputs/products, whereas soft and applied knowledge is more concerned with its ongoing direct usage and application. The ethos of a particular HE institution, department or School itself can also have a significant impact upon teaching and learning practices, despite the need to implement standard guidelines that are required in the UK by the Higher Education Academy. Whatever practice is used by various institutions, Faculties and Schools to teaching/learning facilitation, an important question arises as to whether knowledge gained from learners can become 'public knowledge'. One possible answer may be how this knowledge is fed back into the curricula.

The disciplines and contexts of the learners in this investigation includes both 'soft' and hard disciplines (as all researchers within the organisation require their lifelong and career support needs to be met by the SDO-R). The use of AR is very useful within this investigation, as it can aid the author to more effectively 'drill down' to identify contextually rich data in increasing levels of granularity, following each iterative cycle of AR. The author is fortunate to work inside an organization that operates with an ethos that recognizes the importance of putting 'theory into practice'. As a result, lifelong learning and career support needs that have been identified can be directly implemented by the SDO-R and policy changes needed to be communicated to the Pro-Vice Chancellor for Research and Enterprise (PVC-RE) to ensure that the career development and support needs of research staff are met.

The Boyer Commission (1998) cited by Badley [1] models 'public knowledge' in terms of: 1) marital relationship, 2) impending divorce 3) scholarly relationship or 4) holy alliance. The 'marital' viewpoint view learning facilitators and students as collaborating with one another to achieve a common 
goal. Conversely, others see an 'impending divorce' of where goals and motivations are too different for there to be a proactive harmony. With a scholarly relationship, (the view the author more closely follows), integration, application and teaching/learning, can assist in the areas of reflective practice, providing practical solutions between theory and practice. Knowledge is not just transmitted, but evolves and extends over time. The 'holy alliance' viewpoint perceives knowledge as being unreliable and uncertain. Teaching enables individuals to deal with this uncertainty; where both teachers and learners prefer to remain with 'safe', paradigms and practices and to 'do their best' in an uncertain and unpredictable world.

\section{Ethical Awareness}

Prior to carrying out this research, the author obtained the necessary informed consent of subjects by informing them about what would happen with their feedback. The author recognizes that it would be unethical to have an expectation that the subjects would necessarily agree to participate in the AR. Therefore, researchers were given the opportunity to withdraw their involvement without prejudice or disadvantage to their receipt of free CPD training by the UEA, at any stage; to which their data would be immediately destroyed. Subjects were informed that the intended use of the data was to improve their CPD training and support opportunities and that the findings may also be anonymously referenced for peer reviewed journal publications. The researchers were invited by email to ask if they would be willing to attend one of the series of eight focus group meetings that were held across the UEA. Numbers varied in terms of attendees between fifteen and twenty per focus group, and were mainly attended by specific cohort at each location that were centered upon a particular Faculty, Department or School, although two of the focus groups had a wide range of participants from a number of Faculties across UEA.

\section{Research Method Origins}

A Due to the social constructivist stance of the author, there was a need to consider the method of data collection and reason for its collection, in light of the learning context. The ontological and epistemological stance of the author is listed on the top tier of Figure 1 outlined below as it is the starting point from which both the research process and methods are eventually derived; which includes the usage of contextual based AR.

The decision to collate qualitative data only was due to the collaborative and highly verbalized nature of the focus groups that were held across the university. From the outset of the investigation, critical insights emerged from the very first focus group that were repeated across the other focus groups that were held across UEA. From this base, the author designed a very basic semi-structured focus group list of topics to further investigate and explore these issues.

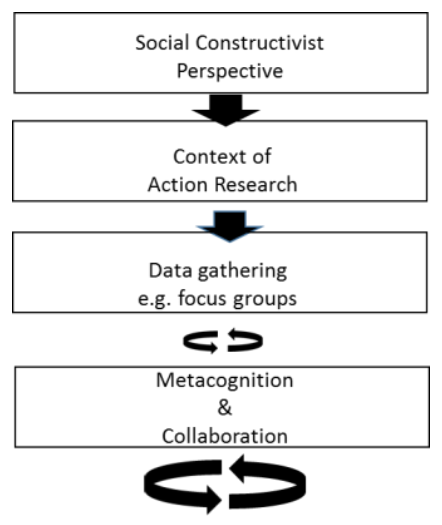

Figure 1. Cycles of Improvement

However, the design of the research tools were left deliberately skeletal to allow for additional topics and themes to emerge during the first cycle of the contextual AR research process. This supported the social constructivist stance of the author that learning and research are inherently social, contextual and collaborative processes. Towards the end of the focus group, the meeting served an additional function of informing participants of the CPD training and services that were on offer. The author believes that future cycles of AR will lead to an evolution and change in the content of the focus group that will also enable participants to reflect and collaborate on CPD that they have already received, within an emergent learning and research process.

The researchers were only available for AR during their lunch hour. One-to-one semi-structured interviews were considered, but this was found to be an unpopular option at a prior focus group event. Furthermore, the author reflected that interviews would be unethical as they would work against the collaborative group based context and would increase the likelihood of skewed results, bearing in mind the smaller number of one-to-one interviews that could take place. Initial enquiries were made into the availability of participants to meet at other times of the day, but researchers were either disinterested, did not want to do it or were too busy to enable this to happen.

In addition to the background to the investigation being communicated via email, it was also verbalized to the participants at the start of each of the focus groups. There were between approximately fifteen to twenty participants that attended each time, with a varied range of ages and of a mixed gender. Each focus group sat in a semi-circle of chairs within a relaxed group setting, with the author facing the 
group either by standing, writing down their comments on a white-board or occasionally sitting down during the coffee break that happened approximately half way through the each focus group event. Each focus group session lasted approximately fifty minutes. It was not taped. This was because the participants did not want to be taped; therefore, it would have been unethical to do so. However, extensive written notes of the group discussions were taken, mainly on the whiteboard by the author and then written down on a notepad after the event. The debate covered the issues of their personal experiences, values and beliefs and thoughts, inclusive of the barriers and enablers that impacted upon their uptake (or lack thereof) of CPD training opportunities on offer at the university. Questions were not formulated at the first focus group with the aim of gathering initial information, and to minimize the potential to introduce 'leading questions' that contained inherent positive or negative assumptions. The author's involvement in the focus group was kept to a minimum, except in the few instances where conversation topics had run their course. Following the initial focus groups, where critical topics for discourse were identified, semi-structured focus group schedules were introduced (although they were kept deliberately skeletal in nature), to enable participants to confirm or refute their relevance to their own individual experiences and context regarding the barriers and enablers to their uptake of CPD.

In addition, the author has kept a journal of each of the focus group events, written within the first hour following each focus group. It contains within it the reflections made by the author each focus group and cycle of AR. In terms of time (nearly twelve weeks during which the eight focus group were held) journal entries were useful in tracking the research 'journey'. To enhance reflection, analysis and ongoing discussion, each new focus group were informed about the issues that had been identified by each previous cohort to further the ongoing and cyclical debate into how to enhance the uptake of CPD by researchers across the university. Although, at the beginning, it was felt that there was too much data about each focus group, the reflective journals have enabled the author to begin to make sense of it. In this first cycle of AR, the author read through the notes and entered them into one master document. This included comments by the author on their reflections over the past three months regarding the focus groups and individual daily interactions that they have had with researchers as part of their job role. As this was being done, additional comments and reflections that were not previously made were achieved and these findings support the view of Moon regarding the inherent benefits of using a research journals to deepen the researcher's understanding of the subject matter under investigation [9]. The data was then coded using keyword analysis; firstly being placed into general themes, then more specific themes, while cross checking with the original notes made alongside those in the master document for added rigor. However, due to being a social constructivist, the author did not attempt to generalize the findings beyond the current research context.

\section{Findings}

The first theme identified an important potential barrier to the uptake of CPD opportunities as being the Project Investigator (PI), who was often perceived to be likely to be unwilling to give the researcher the necessary time to undertake training:

It is unlikely that my manager will give me the time to attend training workshops.

My supervisor does not actively encouraged training. Is that common?

Additional comments add further light to these views or perceptions:

The main barrier is supervisor expectation - it is very difficult to request training when it is not seen as important and as a distraction from research.

A wider range of more in-depth training would be beneficial. Wider encouragement from senior staff and an interest in my career development would be nice.

Another identified theme was an overall perception by researchers that most of the training available would not be relevant to their immediate CPD needs. However, when stating this, most researchers seemed to be only viewing their training needs on a short-term basis in light of their current research project, rather than taking into account their lifelong learning needs:

Nobody asks us what we want to be trained in. But when I have looked to see what is on offer, I find that it isn't relevant to the project that I am working on.

In my current role I barely have time to do my job and certainly no time to undertake training of any sort.

There seems little point in planning a career in the current climate, when early career academics are so numerous and jobs are so few. I will tick as many boxes as I can, but I am under no illusions: luck is the principal determinant in my career path. 
Just over one fifth of respondents actually realized the importance of taking into consideration their lifelong learning needs. Of those that did, there was a request for workshops that would equip them with the skills necessary to set up a consultancy business, along with other skills that would enable them to adapt to a potentially diverse, longer term career path:

Research is a very difficult field to stay employed in. I constantly worry what will happen in a few years when my fixed-term contracts run out. I would find it useful if I received some training on how to set up a consultancy business.

I would like a better sense of what is expected of me (future of Associate Tutor (AT) contracts; requirements to remain $A T$ ) and where my School/department is heading. Then I can decide much better if I even want to stay at UEA, move into teaching or leave academia entirely (all of which I currently see as forms of career development as I am feeling a bit stuck and unsure about my research).

A final major theme identified by the participants was with regards to the area of recognition and value within the university. Whereas some Faculties, Departments and Schools excelled in this area, it was clear that this was not a universal experience across the university:

I am practically invisible to my Head of School. Sometimes, email communications are just sent to the PI's or the academics, and I am left out completely. It makes me feel that I am not a valued member of the School.

Although I feel valued and my contributions are recognized by my direct line manager and to some degree by my department. I feel that at an institution level my work is not recognized at all and my contributions to funding/grant writing, training early career researchers, PhD and undergraduate students is not recognized at all. Researcher "visability" is poor both within and outside of the institute and although training is available and comprehensive, the information on training is not clearly accessible or positively encouraged and often requests to attend courses are viewed negatively or denied.

There is an ongoing problem in some Faculties, Departments and Schools whereby researchers sometimes perceive themselves as being treated less favourably. However, having worked as a researcher for the past fourteen years at another HE institution, the author is aware that this perception is widespread across many other UK HE institutions and it is a view that is often mistaken. Indeed, in many ways, the UEA offers a superior experience for researchers in comparison with many other HE institutions as it possesses a dedicated SDO-R O whose primary role is to support the career support and lifelong learning needs of researchers. This is not the case for many universities and so is a real positive measure taken by UEA to support the training and career support needs of researchers. Many other HE institutions certainly do not provide such a service. However, despite the existence of this superior service, the issue of negative researcher perceptions still remains and needs to be addressed.

\section{Discussion}

Having identified the major themes from the focus groups, it can be argued that a complex picture has emerged regarding the limited uptake of CPD by researchers. The first identified theme seemed to be a major barrier in preventing the uptake of CPD training opportunities; as it was mentioned in all of the focus groups. Researchers are aware that project deadlines are often very tight; leaving them with little time to pursue other activities, inclusive of CPD training. The author realized that it would be extremely difficult to alter many aspects of their working environment and (to some extent) the (real or perceived) inherent organizational culture. To bring about any change, a 'top-down' solution was required. The author was already a member of the Research Staff Working Group (RSWG) that was chaired by the PVC-RE. The RSWG meets each academic semester to discuss the various action points that are outlined in the university's Researcher Concordat. The Concordat consists of an action plan that contains a series of deliverables (that need to be evidenced); in order for the university to retain hold of its HR Excellence in Research Award. As the RSWG has a strategic responsibility to identify and action key action points that will benefit the careers and working conditions of researchers, this was the ideal vehicle to use to raise issues and themes identified by the focus groups. Indeed this approach worked extremely well and within one month of alerting the RSWG of the concerns of researchers in not being granted the time to undertake CPD, the PVC-RE had raised this issue at the following Executive Team (ET) meeting. As a result, the ET endorsed a change in university policy whereby all staff were given the right to request a minimum of two days CPD per year.

The second identified theme concerned the lack of perceived use or 'relevance' of the CPD training. The author found that researchers only viewed training in terms of their current research projects. 
Table 1. Themes, reflections and strategy

\begin{tabular}{|c|c|c|c|}
\hline Identified Theme & Source & Reflections & $\begin{array}{l}\text { Action Strategy and } \\
\text { future investigations }\end{array}$ \\
\hline $\begin{array}{l}\text { Perception that PI's } \\
\text { and Heads of School } \\
\text { would be reluctant to } \\
\text { offer researchers time to } \\
\text { undertake CPD }\end{array}$ & $\begin{array}{l}\text { Focus groups \& face-to- } \\
\text { face interactions with } \\
\text { researchers }\end{array}$ & $\begin{array}{l}\text { Researchers have 'got } \\
\text { used' to not expecting to } \\
\text { ask (or be asked) what } \\
\text { their CPD lifelong } \\
\text { learning and support } \\
\text { needs are }\end{array}$ & $\begin{array}{l}\text { Approach Research Staff } \\
\text { Working Group (RSWG) } \\
\text { and stress how university } \\
\text { policy change to have } \\
\text { two days minimum CPD } \\
\text { from the Executive Team } \\
\text { (ET) will boost researcher } \\
\text { morale (to be analysed in } \\
\text { six months) and meet a } \\
\text { major action point in the } \\
\text { HR Excellence in } \\
\text { Research Award }\end{array}$ \\
\hline $\begin{array}{l}\text { Perception training not } \\
\text { relevant to their training } \\
\text { needs and also not taking } \\
\text { a 'longer term' view of } \\
\text { training beyond the life of } \\
\text { their immediate research } \\
\text { project }\end{array}$ & Focus groups & $\begin{array}{l}\text { Researchers have not } \\
\text { looked into what CPD } \\
\text { training is on offer for } \\
\text { their lifelong learning } \\
\text { needs, which was } \\
\text { corrected at the end of the } \\
\text { focus groups by the } \\
\text { author of this paper } \\
\text { highlighting the 'bigger } \\
\text { picture'. Researchers } \\
\text { made aware that they can } \\
\text { make requests to SDO-R } \\
\text { for new workshop } \\
\text { training topics }\end{array}$ & $\begin{array}{l}\text { Further to the focus } \\
\text { groups, the SDO-R needs } \\
\text { to disseminate the } \\
\text { 'lifelong' learning needs } \\
\text { message to researchers so } \\
\text { that they look in greater } \\
\text { detail into what is on } \\
\text { offer (and also } \\
\text { communicate with the } \\
\text { SDO-R about training } \\
\text { that is not currently on } \\
\text { offer that they also want } \\
\text { for the future). Efficacy } \\
\text { of this approach to be } \\
\text { assessed in six monthly } \\
\text { cycles of AR }\end{array}$ \\
\hline $\begin{array}{l}\text { Awareness that research } \\
\text { may not be a lifelong } \\
\text { career }\end{array}$ & Focus groups & $\begin{array}{l}\text { Inaction (or lack of } \\
\text { confidence in some } \\
\text { instances) to contact } \\
\text { SDO-R to put in place } \\
\text { training on how to set up } \\
\text { a consultancy business. } \\
\text { As a result of the focus } \\
\text { groups, now successfully } \\
\text { communicated and } \\
\text { researchers feel more } \\
\text { confident to state their } \\
\text { needs and demands to the } \\
\text { SDO-R }\end{array}$ & $\begin{array}{l}\text { Set up as soon as possible } \\
\text { the workshops that meet } \\
\text { the training needs of } \\
\text { researchers (whether } \\
\text { project-related or not) so } \\
\text { that their lifelong learning } \\
\text { needs and support goals } \\
\text { are met. Maintain regular } \\
\text { contact with researchers } \\
\text { via focus groups and } \\
\text { email questionnaires, to } \\
\text { keep up to date with their } \\
\text { needs and to inspire } \\
\text { confidence in researchers } \\
\text { to communicate their } \\
\text { needs more effectively }\end{array}$ \\
\hline $\begin{array}{l}\text { Perceived lack of } \\
\text { recognition and value } \\
\text { given to researchers, } \\
\text { whether this is being } \\
\text { omitted from the } \\
\text { mainstream channels of } \\
\text { communication } \\
\text { Faculties, Departments, } \\
\text { Schools (or similar) }\end{array}$ & $\begin{array}{l}\text { Focus groups and face-to- } \\
\text { face interactions with } \\
\text { researchers }\end{array}$ & $\begin{array}{l}\text { Researcher Award Days } \\
\text { not present in all } \\
\text { Faculties and Heads of } \\
\text { School need to be made } \\
\text { more aware of the need to } \\
\text { include all staff in email } \\
\text { communications to } \\
\text { promote 'inclusiveness' }\end{array}$ & $\begin{array}{l}\text { PVC-RE to approach } \\
\text { Heads of School to } \\
\text { inform of need for } \\
\text { inclusive } \\
\text { distribution listing and } \\
\text { RSWG to communicate } \\
\text { and monitor 'Researcher } \\
\text { Award Days' as evidence } \\
\text { for the Researcher } \\
\text { Concordat Action Plan }\end{array}$ \\
\hline
\end{tabular}


When the SDO-R explained to them the importance of considering the lifelong learning needs, to some degree attitudes began to show signs of changing as researchers began to view their career support and training needs beyond the project 'bubble' within which they current operate. This second theme links to those researchers (just over fifth) who do realise that research may not be a lifelong career for them, but feel uncertain as to what to do about it and how to ask for support. It is the role of the SDO-R to inspire confidence in researchers to ask for assistance of this type and this can be achieved by setting up workshops that example this, such as 'business startups' and consultancy training workshops, which the SDO-R has now done. As with all identified themes, the author will monitor their uptake and effectiveness over time within cyclical assessments of AR every six months via a series of focus groups and face-toface communications. It is expected that each annual update of the training programme will be impacted directly form the investigations and research findings brought about by this study.

The final identified theme regarding the perceived lack of recognition and value within the institution, may not be a deliberate act of exclusion, but more one of a likely practical issue, as researchers can be very transient at a $\mathrm{HE}$ institution and keeping email distribution lists up-to-date can be difficult at best. However, this does not detract from the fact that researchers believe that they are not being seen as 'part of the school' due to being excluded from a number of school-wide email communications that their academic colleagues receive. Further to the issue of the need for at least two days annual CPD to be introduced, further measures were taken by the PVC-RE to ensure that researchers feel more valued within their respective Faculties, Departments and Schools.

As a result of the finding being reported to the RSWG and actioned by the PVC-RE, outlining the positive impact upon researcher staff along with helping the university in retaining its HR Excellence in Research Award, the PVC-RE has visited each of the Heads of School to request that researchers are included in school communications. The RSWG has also requested that each Faculty does more to provide 'Researcher Award Days' whereby Awards and prizes are given to researchers that have excelled in their particular research projects each year. This has been done so as to enable researchers to feel more valued within the university. The activities of Faculties regarding 'Researcher Award Days' will also be monitored and recorded.

It is important to state that the author has just completed their first AR spiral. There are still issues (outlined within the final column of Table 1) and the author will explore these issues further. The author views $A R$ as being a lifelong process. It will change and amend itself over time to meet an individual's evolving support and lifelong learning needs [12]. Furthermore, it will differ according to the context, group and the particular social milieu of learners and it is essential that there is an ongoing and cyclical process of feedback in order for the needs of participants to be adequately met. Not only will this improve the CPD process, but it will meet requirements expected of a 'reflective practitioner' [10].

The author views the first cycle of outcomes as valid as they are providing valuable insights into what affects the decision of researchers in HE to undertake CPD training. The beliefs and values of the author remain unchanged i.e. they are firmly rooted within social constructivism. The author also retains a strong belief in the importance learner equity, freedom, social balance and student empowerment. It could be argued that $A R$ is not 'formal research' that can be generalizable beyond the context in which it is situated and that it cannot therefore, inform $\mathrm{HE}$ to enact political or social change. However, what it can do, is to provide 'indicators' for more formal procedural or policy changes. This investigation has been exampled this, with the changes that have been enacted by the PVCRE and ET via use of the vehicle of the RSWG. These findings and process serve as an example of how, under certain conditions, real and lasting positive change can be brought about in a timely fashion within a HE institution over a relatively short period of time.

\section{Conclusions}

The author acknowledges that AR may not be seen by all as a valid and reliable approach and method of research. It certainly cannot be generalized beyond this particular research context. However, the author believes that it possesses a validity as it has aided in the identification of important areas of change that have led to an effective action strategy within its very first cycle. At all stages of the initial cycle, there has been an attempt to follow ethical guidelines and frameworks. The first cycle has highlighted the reasons behind why researchers feel uncomfortable asking their PI's for the time required to undertake CPD training. The favourable conditions surrounding the remit of the RSWG and the Researcher Concordat proved to be an effective vehicle by which the PVC-RE could approach the ET to request that two full days CPD per annum to overcome this (real or perceived) barrier. Researchers also reported some confusion on the type of training that they consider to be 'relevant' to them; often failing to take into consideration their longer-term CPD training needs. In order to boost researcher morale and to offer a genuine portfolio of lifelong learning support, CPD also needs to cover non-academic areas, inclusive of 
equipping researchers with the ability to pursue career moves outside of academia and this need has now been met. For those researchers who choose to remain within academia, they stated that it was important they felt valued and that their achievements were recognised. As a result of this feedback, 'Researcher Award Days' are being expanded and the Heads of School have been instructed by the PVC-RE to included researchers in their future school-wide email communications.

The socio-economic argument towards promoting and facilitating the lifelong and career support needs of researchers is very strong. The UK Higher Education sector, when even viewed in purely economic terms, plays a significant role in underpinning economic growth, firstly with the provision of training for students in higher levels to join the future workforce, as well as providing ground-breaking research. As sector, HE also provides jobs for the UK workforce year-on-year offers a sizeable contribution to the UK 's economy. Therefore, effectively supporting the UK's talented pool of HE researchers, benefits both the particular institution doing it as well as the wider economy. Within each cycle of AR, the SDO-R will improve their understanding of the needs of the institution's research staff and when this is coupled with the strategic aims of the institution, improvements can be rapid, up-to-date, targeted and effective within this particular context and environment.

The initial findings of this first cycle of $\mathrm{AR}$ provide a clear indication of the benefits of further strengthening and expanding communication networks with research staff; alongside the provision of efficient and effective support systems that meet their lifelong learning and career support needs. AR provides the SDO-R with an effective research and communication vehicle that will enable them to obtain up-to-date data in this regard, which can then be fed back to the RSWG, should any universitywide policy implementation be required. Following this, the SDO-R can update the research staff on progress achieved as well as directly implement the provision of training workshops or other types of support that have been requested. As this type of research is collaborative, the SDO-R acts as an invaluable conduit between the research staff and the Executive staff at the university. The SDO-R also acts as an advisor to research staff, for example, in outlining the importance of researchers viewing their training needs outside of the current 'research bubble' in which they are operating.

This type of research design, analysis and action based activity is a 'bottom up' process where it is the subjects being investigated that play a significant part in guiding the researcher towards what needs to be investigated and analysed. As such, AR serves as an excellent method in which to move forward positive and proactive change within an institution.
As a result of this process, the author believes that they are better able to both identify and deliver, improvements in the lifelong learning and career support needs of researchers.

The author is looking forward to implementing and evaluating the action strategy that was derived within the first AR cycle, and beyond, that within a lifelong cycle of AR as its impact is assessed and actions amended and updated to reflect these needs that may also change over the course of both time and context.

There will most likely be other HE institutions that are utilizing a similar version of AR (or one of the three available approaches), with the aim of bringing about positive institutional change. However, from the standpoint of social constructivism and contextual AR, the author is not attempting, nor makes any claims that they can bring about any change to the organizational culture (if indeed this is required at all); but is instead attempting to bring about changes to policy and practice that will improve the uptake of CPD for researchers. However, what can be achieved is to 'scholarly' inform colleagues of the AR findings [1]. What they do with this feedback is yet to be seen, although in the right context of strong 'bottom up' communication networks, the feedback received can be swiftly channeled to enact substantial positive change. To bring about effective change, "codes...values of equity, integrity and justice" form a critical part to any process [5]. However, within some entrenched organizational cultures, the strongest and most effective motivators are strategic goals such as the HR Excellence in Research Award and subsequent UEA action plan that is aligned with a progressive PVC-RE and Executive Team that have both open and responsive communication channels. The author is looking forward to seeing additional progress outcomes in the next cycle of AR.

\section{References}

[1] G. Badley, "A Really Useful Link Between Teaching and Research", Teaching in Higher Education, Vol 7, No. 4, 2002, pp.443-455.

[2] A. Biglan, "The Characteristics of Subject Matter in Different Academic Areas", Journal of Applied Pyschology, Vol 57, No.2, 1973, pp. 192-203.

[3] W. Carr and S. Kemmis, Becoming Critical: Education, Knowledge and Action Research, Falmer Press, Basingstoke, 1986.

[4] H. Gardner, H. (1999) Intelligence Reframed. Multiple Intelligences for the 21st Century, Basic Books, New York, 1998. 
[5] S. Holroyd, Are Assessors Professional? Student Assessment and the Professionalism of Academics, London, Sage, 2000.

[6] D. Kolb, Experiential Learning. Experience as the Source of Learning and Development, Englewood Cliffs, New Jersey, Prentice-Hall, 1984.

[7] K. Lewin, "Action Research and Minority Problems", Journal of Social Issues, Vol 2, No. 4, 1946, pp.34-46.

[8] F. Martin and R. Saljo, "On Qualitative Differences in Learning - Outcome and Process", British Journal of Educational Psychology, Vol 46, 1976, pp. 4-11.

[9] J. Moon, Learning Journals: A Handbook for Academics, Students and Professional Development, Kogan Page, London, 1999.

[10] M. Prosser and K. Trigwell, Understanding Learning and Teaching, Society for Research into Higher Education, Buckingham, Open University Press, 1999.

[11] L.S. Vygotsky, Mind in Society: The Development of Higher Psychological Processes, Translated by Blunden, A. and Schmolze, N., 1930, 4th ed, 1978, Cambridge, Harvard University Press, 1930.

[12] L. Worrall and F. Bell, "Metacognition and Lifelong e-Learning: A Contextual and Cyclical Process", $e$ Learning, Vol 4, No. 2, 2007, pp. 161-171. 